\title{
Growth Cone Morphology and Trajectory in the Lumbosacral Region of the Chick Embryo'
}

\author{
KATHRYN W. TOSNEY² AND LYNN T. LANDMESSER \\ Physiology Section, Biological Sciences Group, The University of Connecticut, Storrs, Connecticut 06268
}

\begin{abstract}
We quantitatively analyzed several features of orthogradely labeled peripheral growth cones in the lumbosacral region of the chick embryo. We compared motoneuron growth cones in regions where they appear to express specific directional preferences (the plexus region and regions where muscle nerves diverge from main nerve trunks), which we operationally defined as "decision regions," to motoneuron growth cones in other pathway regions (the spinal nerve, nerve trunk, and muscle nerve pathways) which we termed, for contrast, "non-decision regions." We found that motoneuron growth cones are larger, more lamellepodial, and have more complex trajectories in decision regions. Sensory growth cone populations, which are thought to be dependent upon motoneurons for outgrowth (Landmesser, L., and $\mathbf{M}$. Honig (1982) Soc. Neurosci. Abstr. 8: 929), do not enlarge or become more lamellepodial in motoneuron decision regions, suggesting that this local environment does not affect all species of growth cones equally and that the alterations in motoneuron growth cones in these regions may be relevant to their specific guidance. In addition, the resemblance between the sensory population and other closely fasciculating growth cones lends support to the suggestion that sensory neurons utilize motoneuron neurites as a substratum. We suggest that the convoluted trajectories, enlarged size, and more lamellepodial morphology of motoneuron growth cones in decision regions is either related directly to the presence of specific cues that guide motoneurons or to some aspect of this environment that allows them to respond to specific cues.
\end{abstract}

Ramón y Cajal (1937) intuitively recognized the growth cone as the searching organ of the neuron. This assessment has been validated by tissue culture work which shows that the growth cone can respond to its local environment in specific ways. For instance, given a choice between substrata, a growth cone will move onto a more adhesive one (Letourneau, 1975a) or one derived from its target (Bonhoeffer and Huf, 1982), and growth cones will turn and

Received August 22, 1984; Revised January 7, 1985;

Accepted January 29, 1985

${ }^{1}$ We thank V. Argiro for helpful discussions during the course of this work and L. Dahm, N. Davis, B. Gray, and H. Tanaka for critical evaluation of the manuscript. This work was supported by National Institutes of Health Grant NS 19640 and by Muscular Dystrophy Association and National Institutes of Health postdoctoral fellowships.

${ }^{2}$ To whom correspondence should be sent, at her present address: Natural Science Building, Division of Biological Sciences, The University of Michigan, Ann Arbor, Ml 48109. move toward a source of nerve growth factor (NGF) (Gunderson and Barrett, 1980). An alteration in growth cone direction can result from a very local interaction with the environment. For instance, preferential adherence of a few filopodia results in movement toward the more adhesive substratum (Letourneau, 1975b; see also Bray, 1973,1979 ), and the turning response to an NGF gradient has been suggested to result from the extension of more filopodia toward the uphill side of the gradient (Gunderson and Barrett, 1980).

The most convincing evidence that growth cones respond specifically to environmental cues within their filopodial range in the embryo as well as in vitro comes from studies in the grasshopper. These growth cones abruptly alter their direction of outgrowth at local landmarks that include neuronal guidepost cells, muscle pioneers, particular axons, and limb-segment boundaries (Bentiey and Keshishian, 1982; Goodman et al., 1982; Ho et al., 1983; Taghert et al., 1982; Raper et al., 1983a, b; Bastiani et al., 1984; Bentley and Caudy, 1984), may follow local polarity cues (Bentley and Caudy, 1984), and do not require a long-distance cue from the target (Berlot and Goodman, 1984). Guidepost cells and certain axons have been shown to be necessary for precise innervation, since when they are ablated, growth cones make mistakes (Bentley and Caudy, 1983; Raper et al., 1984).

Intriguing morphological differences in grasshopper growth cones correlate with their position relative to local cues. For instance, growth cones become progressively larger along a substratum that has been suggested to increase in adhesiveness (Bentley and Caudy, 1984) and are larger and more complex when confronted with divergent pathways (Taghert et al., 1982; Bentley and Caudy, 1984). One of the objectives of the present paper was to describe at a comparable level of detail vertebrate growth cones that were making specific directional decisions.

There is cogent evidence that local areas are also of particular importance to the specificity of motoneuron growth cone navigation in the chick hindlimb system. One of these areas is the plexus region at the base of the leg. Neurites which are spatially intermixed in the spinal nerves sort out in this region to assume a specific fiber order and to enter the correct nerve trunk (Lance-Jones and Landmesser, 1981a). In addition, when neurites alter their direction of travel in order to project correctly following experimental manipulations, they do so predominantly within the plexus region (Lance-Jones and Landmesser, 1981b; Ferguson, 1983; Whitelaw and Hollyday, 1983). This local fiber rearrangement cannot be explained by passive models of axon guidance (cf. Horder and Martin, 1978) and strongly suggests that sorting out requires specific cues. Since neurites can sort out normally in the plexus region when all more distal tissues have been ablated, these cues are likely to be local (Tosney and Landmesser, 1984). Whereas the increased numbers of cells in the vertebrate are unlikely to allow a one-to-one interaction between individual growth cones and individual cellular landmarks, the plexus region may be analogous to landmarks in the grasshopper embryo in that growth cones respond to local cues and make specific directional decisions within this spatially restricted region. 

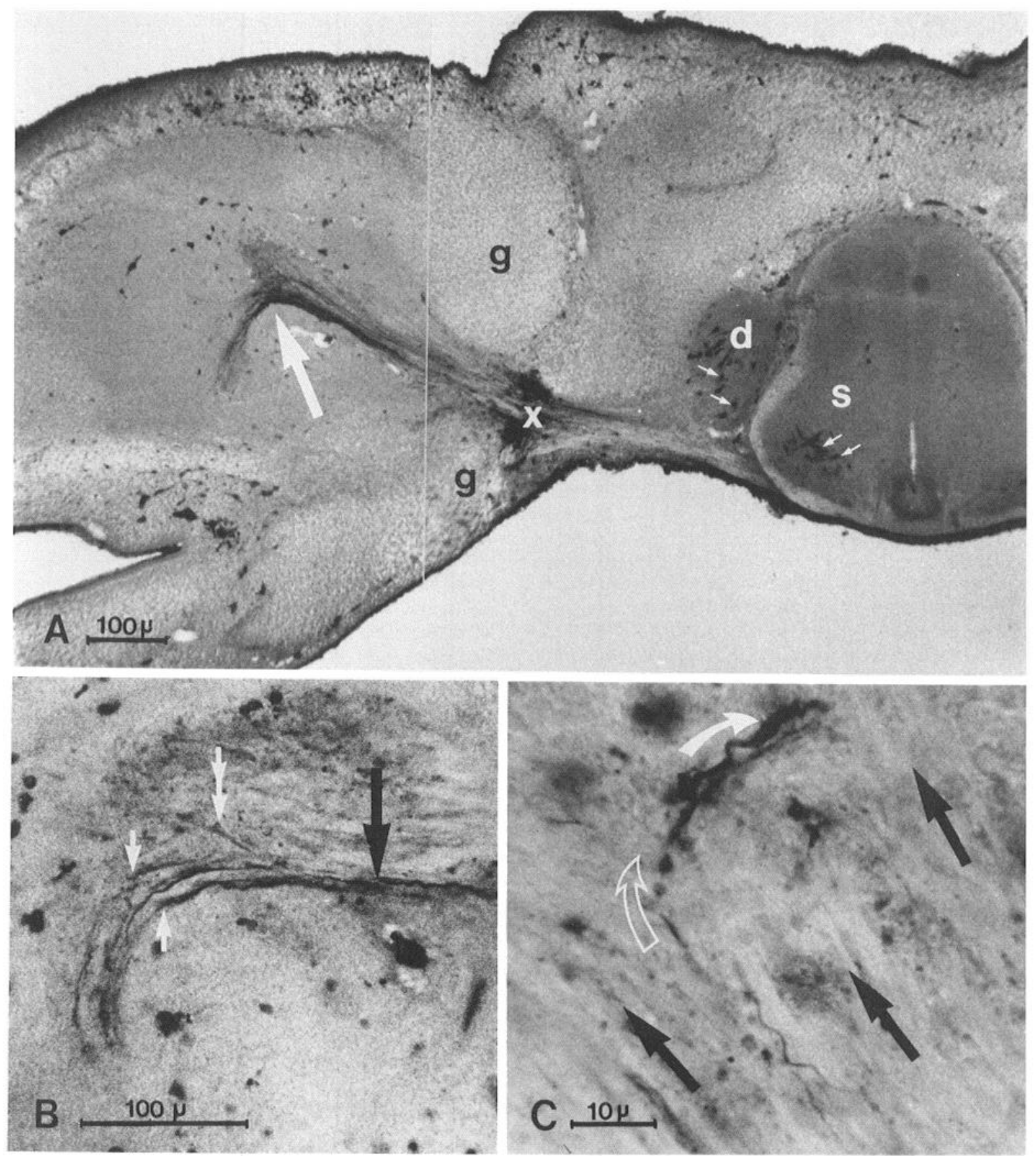

Figure 1. Muscle nerve decision regions. A, St 28 embryo in which HRP has been injected into the plexus region ( $x$ ) just proximal to the gap in the pelvic girdle precursor $(g)$ through which neurites enter the leg. A proportion of the neurites have picked up the label and transported it retrogradely to their somata (small white arrows) in the spinal cord (s) and dorsal root ganglion $(d)$ and orthogradely to their terminations in the muscle masses. Within the leg, neurites turn dramatically at a muscle nerve decision region (large white arrow) where a muscle nerve diverges from the main nerve trunk. $B$, Higher magnification of a muscle nerve decision region from a st 28 embryo in which a few motoneuron neurites have been orthogradely labeled by HRP injected into the spinal cord. The profiles, which lie closely together in the proximal nerve trunk (large black arrow) have diverged and turn at different positions within the muscle nerve decision region (small arrows). One growth cone (double arrows) has diverged in the opposite direction. $C, A$ labeled growth cone (curved white arrow) within a muscle nerve decision region has turned abruptly (curved hollow arrow) and crosses unlabeled neurites that course perpendicular to its pathway. The direction of travel of unlabeled neurites is indicated by black arrows.

Growth cones must also make specific directional decisions within the leg. They are confronted with a choice of possible directions when they reach the region where muscle nerve pathways diverge from the main nerve trunks. This choice has been shown to be made with a high degree of precision (Lance-Jones and Landmesser, 1981a; Hollyday, 1983; Tosney and Landmesser, 1985a). In addition, growth cones take independent trajectories when entering a muscle nerve. This behavior is less consistent with passive models of axonal guidance and suggests that growth cones choose the correct pathway independently of one another (Tosney and Landmesser, 1985a). We therefore propose that growth cones respond individually and actively to specific cues in this region.

In contrast, neurites in the spinal nerve and nerve trunk pathways appear to retain a constant fiber order during normal outgrowth and following experimental manipulations (Lance-Jones and Landmesser, 1981a, b; Summerbell and Stirling, 1981; Tosney and Landmesser, 1985a). Several workers have proposed that growth cone progression is "passive" in these regions in that their ordered out- 

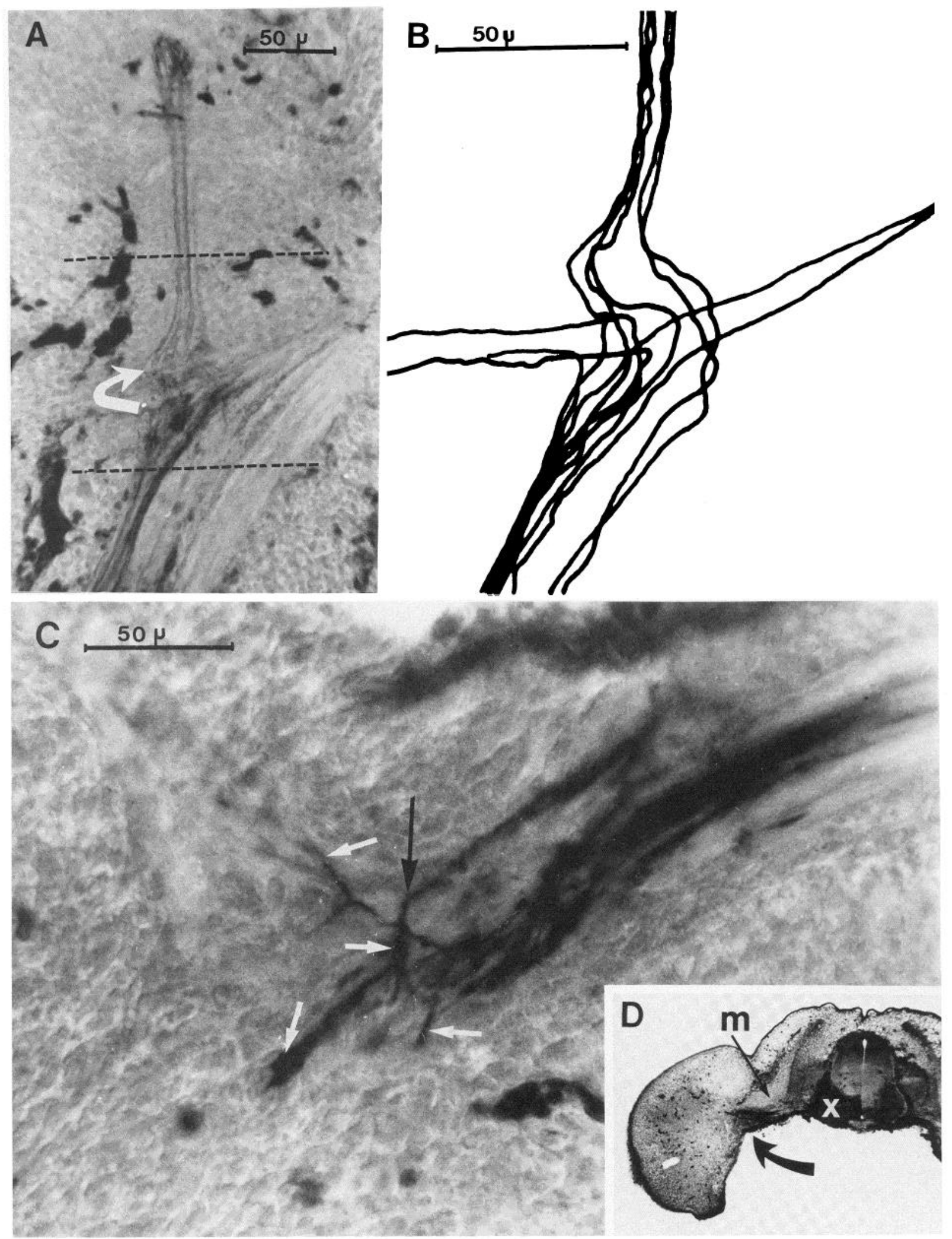

Figure 2. The plexus region. A, Labeled motoneuron neurites that travel parallel to one another in the spinal nerves (bottom), dramatically alter their trajectories in the plexus region (middle-arrow), and resume straight trajectories within the nerve trunk until they reach a muscle nerve decision region (top). B, Camera lucida drawings of labeled profiles within the region between the dashed lines in $A$ show the complexity of trajectories in this region. Since individual profiles are seldom continuously visible within one focal plane, camera lucida drawings are necessary to demonstrate the complexity of profiles. $C$, Labeled motoneuron growth cones (white arrows) cross over one another in the plexus region from the embryo shown in $D$. One abrupt alteration in trajectory is indicated by the black arrow. The trajectories in the spinal nerve, at right, are relatively straight. $D$, HRP injected into the cord $(x)$ has labeled motoneuron neurites and growth cones. The plexus region (curved arrow), lying just ventral to the myotome $(m)$, is shown in $C$. 

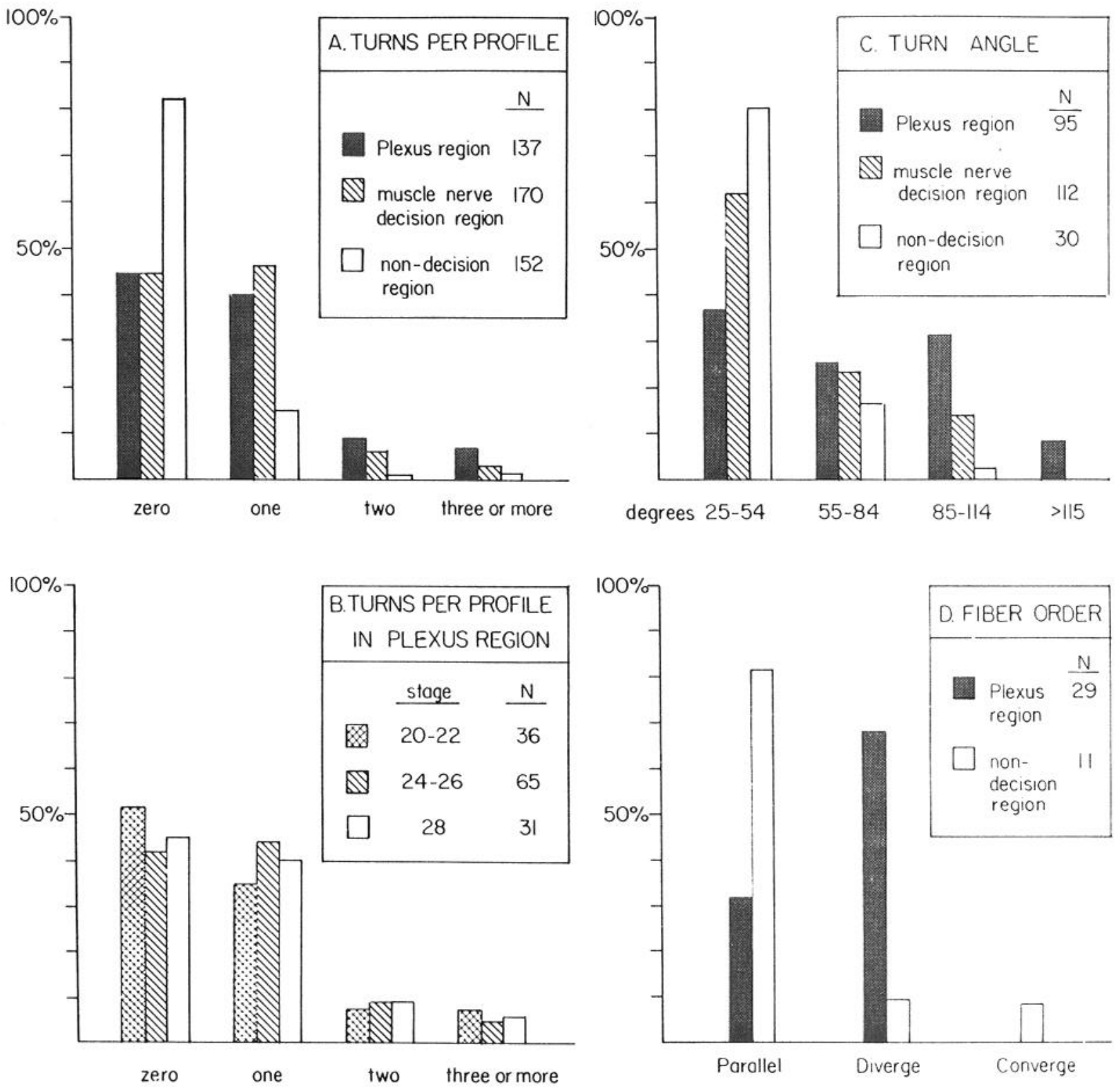

Figure 3. Alterations in trajectory. The number of turns greater than $25^{\circ}(A$ and $B)$, the angle of turns $(C)$, and the degree of divergence among formerly adjacent profiles $(D)$ in the terminal $50 \mu \mathrm{m}$ of motoneuron profiles are shown as a percentage of each population identified in the keys. Profiles in decision regions tend to have more turns per profile $(A)$, turn at greater angles $(C)$, and diverge more often $(D)$, and the number of turns per profile in the plexus region is similarly distributed at all stages $(B)$.

growth requires little or no response to specific cues (Landmesser, 1980, 1984; Lance-Jones and Landmesser, 1981a, b; Lewis et al., 1983; Whitelaw and Hollyday, 1983; Tosney and Landmesser, 1985b). This hypothesis is consistent with evidence that a relatively normal gross anatomical pattern of outgrowth will develop under experimental conditions that channel neurites into foreign territories where they are allocated among muscle nerves and targets rather indiscriminately (Morris, 1978; Lance-Jones and Landmesser, 1981b; see also Hollyday, 1981; Lewis et al., 1983).

We sought empirical terms for these regions that would reflect the differences in neurite behavior within them. We chose to call the plexus region and the region where incipient muscle nerve and nerve trunk pathways diverge "decision regions." We termed the spinal nerve, nerve trunk, and muscle nerve pathways "non-decision regions" in order to emphasize the contrast between the regions. By using this term we do not mean to imply that specific cues are not available in non-decision regions but rather that growth cone advance in these regions is more likely to be regulated by general pathway constraints than by specific cues. The present study at least partially validates the use of these terms by showing that populations of motoneuron growth cones show significant differences in morphology and trajectory in decision and non-decision regions.

We were also interested in comparing motoneuron and sensory growth cones quantitatively, since descriptive and experimental observations suggest that these populations may use different mechnisms to achieve specific outgrowth (Landmesser and Honig, 1982; Landmesser et al., 1983; L. T. Landmesser and M. G. Honig, manuscript in preparation; see also Honig, 1980; Lewis et al., 1981). These studies indicate that sensory neurons require motoneurons in order to project down muscle nerve pathways, and suggest that those cues that guide motoneuron growth cones into a particular muscle nerve are insufficient to guide the growth cones of sensory neurons into the same pathway. This interpretation is consistent with the results we report here, which show that the morphology of sensory growth cones is not significantly different in motoneuron decision and non-decision regions. 


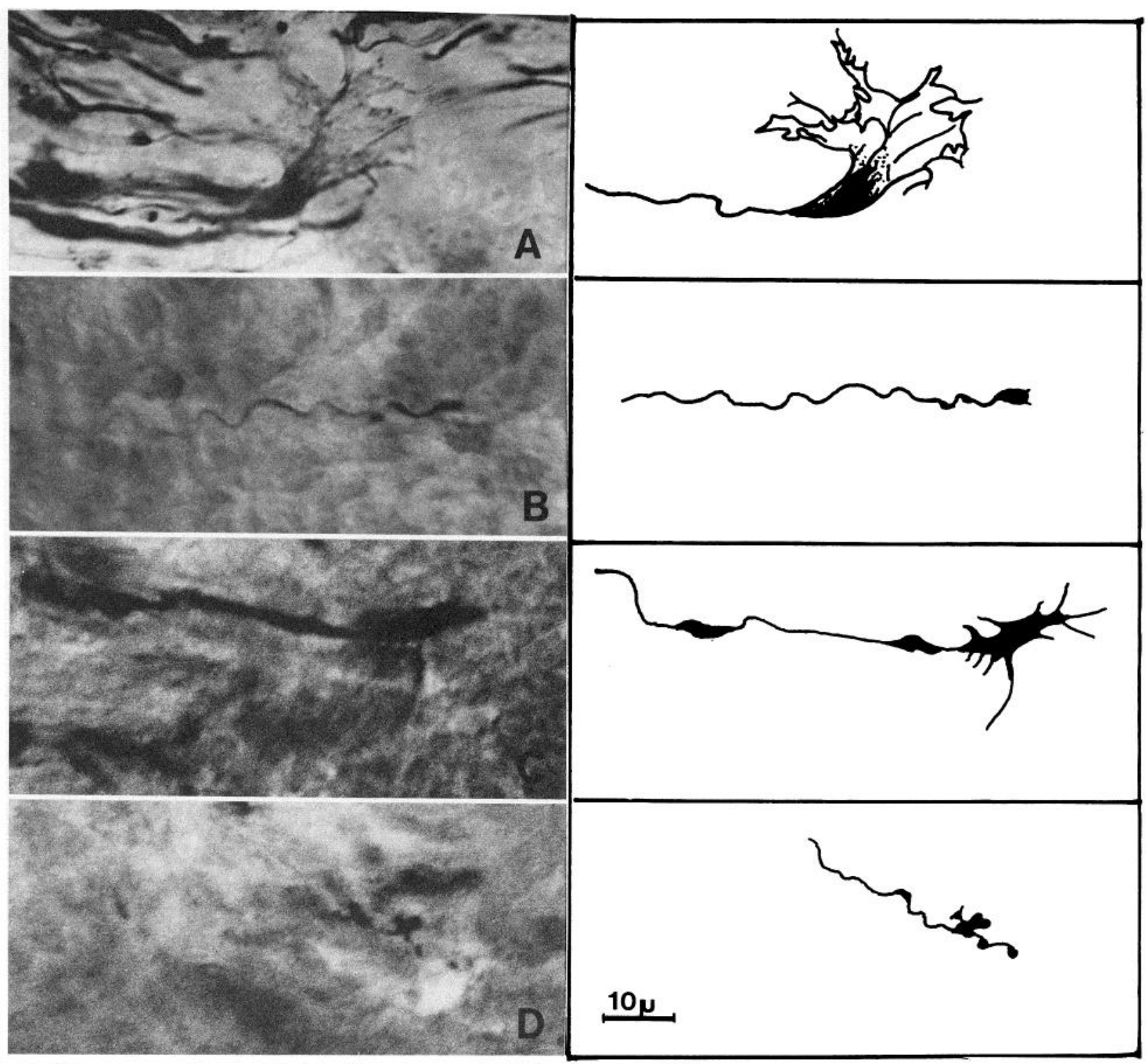

Figure 4. Motoneuron growth cones. Photographs and camera lucida drawings at $\times 100$ illustrate the typical morphologies of motoneuron growth cones in different regions: a lamellepodial growth cone from the plexus region at st $24(A)$, a varicose growth cone from the spinal nerve at st $22(B)$, a filopodial growth cone from the plexus region at st $26(C$; note that many of the filopodia extended out of the focal plane and could only be documented in the camera lucida drawing), and a varicose growth cone within the target at st $30(D)$.

\section{Materials and Methods}

Embryos $(N=33)$ were removed to an oxygenated Tyrode bath and staged using Hamburger and Hamilton (1951) criteria, and then were decapitated and eviscerated; the cartilage surrounding the ventral spinal cord then was removed. Ten percent horseradish peroxidase (HRP) in Tyrode's solution was pressure injected into small regions of the cord, individual sensory ganglia, or, in a few cases, the peripheral nerves. These samples were then processed for visualization of label and plastic embedding and were serially sectioned at $25 \mu \mathrm{m}$ as in Tosney and Landmesser (1985a).

This HRP technique intensely labels a percentage of the neurons present at the injection site from their somata to their growth cone, thus allowing the trajectory and identity of the neuron to be established. Examination with the transmission electron microscope of similarly prepared thin-sectioned material showed that the HRP reaction product occurred diffusely throughout the neuronal cytoplasm, resulting in complete labeling of the neurons, including fine filopodia and veils (Tosney and Landmesser, 1985b). The fixation and plastic embedding protocol we used was found to result in superior preservation, allowing the details of individual growth cone morphology and trajectory to be examined for the first time in this system.

Since the growth cone and its neurite are seldom restricted to a single focal plane, we established the three-dimensional structure by means of camera lucida tracings. We drew 1338 individual growth cones and their neurites at a final magnification of $\times 100$. In cases in which only a few neurites had been labeled, we could determine the details of growth cone anatomy within each $25-\mu \mathrm{m}$ section and could often follow profiles from section to section. Nomarksi optics helped us to identify individual trajectories when profiles crossed one another and aided in visualization of fine veils and filopodia. Each field of growth cones that we drew with the camera lucida was retraced on tracing paper and coded by number before measurement and analysis. Decoding and reference back to the original camera lucida tracings gave us the position of each growth cone and allowed us to assign each to a particular decision or non-decision region.

The following positional criteria were used to classify growth cones by region. The plexus region lies at the base of the leg and is bounded dorsally by the myotome and ventrally by the posterior cardinal vein; on the mediallateral axis it extends $150 \mu \mathrm{m}$ into the leg in the anterior, crural plexus (see Fig. $2 \mathrm{C}$ ) and $250 \mu \mathrm{m}$ into the leg in the posterior, sciatic plexus. Muscle nerve decision regions were defined by a radius of $75 \mu \mathrm{m}$ around the point where a muscle nerve diverged from a nerve trunk (see Fig. $1 A$ ). We examined growth cones in muscle nerve decision regions leading to the sartorius, femorotibialis, ischioflexorius, caudilioflexorus, and posterior iliofibularis muscles. 

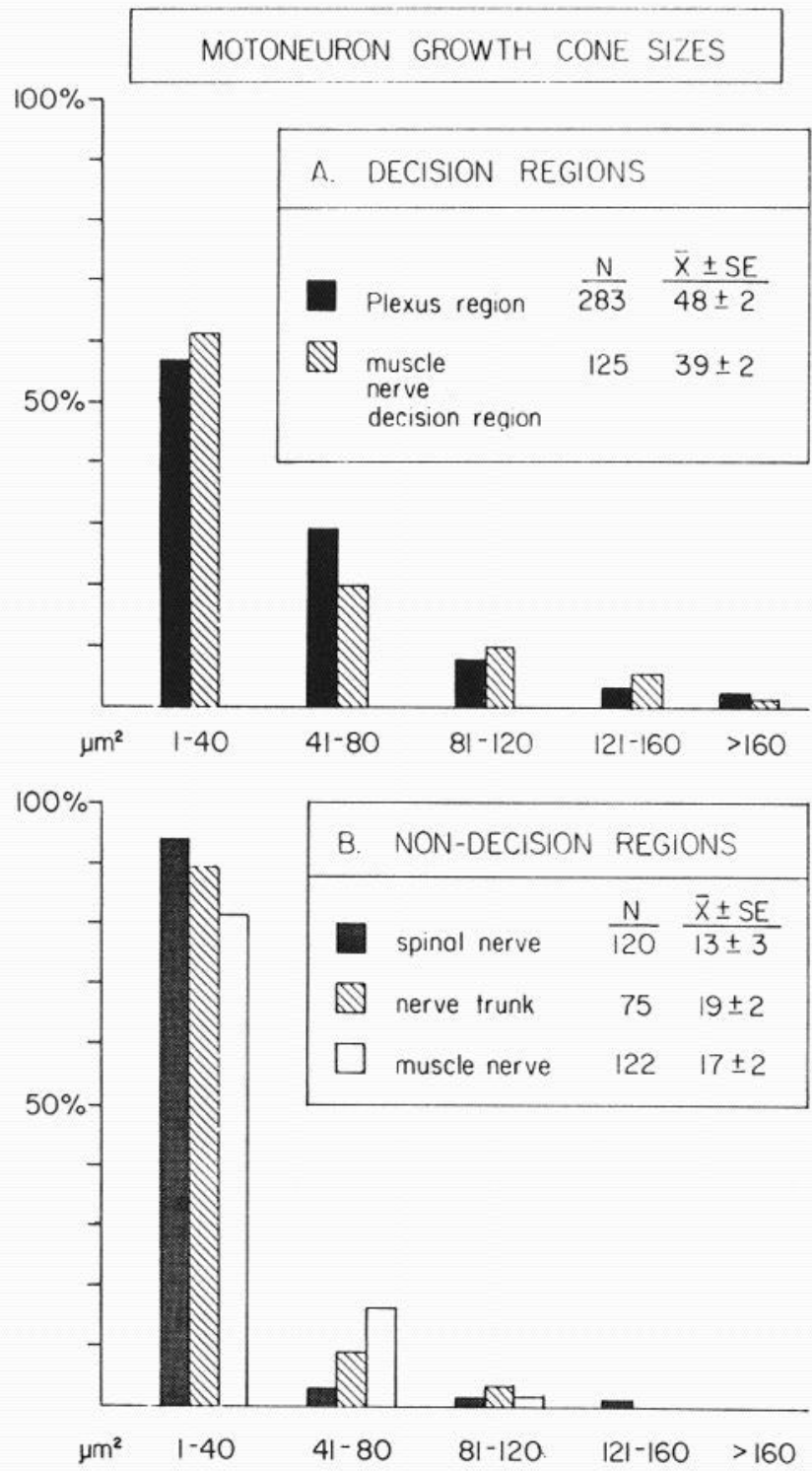

Figure 5. Size of motoneuron growth cones correlates with position. The proportion of populations identified in the key in each size class, where the size is the product of the width and length of the growth cone, is shown in different decision $(A)$ and non-decision $(B)$ regions. Within decision regions, the growth cone populations are skewed toward larger sizes.

Since we were unable to observe the growth of axons in time, we attempted to approximate the recent trajectory taken by a growth cone by examining the trajectory of its axon. However, axonal trajectories may not be a faithful indicator of the route followed by a growth cone, especially when they are examined at later developmental stages. For example, the complexity of turns could be exaggerated by spatial alterations in the environment that could tow neurites in various directions. In addition, much of the length of the neurite is laid down by intercalary growth after synapses are formed (see Bray, 1983). We attempted to minimize these problems by examining the shape of idividual profiles soon after they had passed through a region and by analyzing only the terminal $50 \mu \mathrm{m}$ of neurite just proximal to the growth cone. The assumption that the growth cone trajectory in these cases is reproduced by the shape of the profile is probably valid, since in some highly adhesive tissue culture environments the neurite reproduces on a fine level the pathway taken by the growth cone (Luduena, 1973). The outgrowing nerve is likely to present a highly adhesive substratum, since interneuronal contacts appear to be preferred over other substratum choices and neurites often spread on each other within the nerve (Tosney and Landmesser, 1985b). In addition, our results show that neurites are unlikely to be passively pulled into their complex configurations by alterations in the spatial arrangements of the environment during the period of our study, since

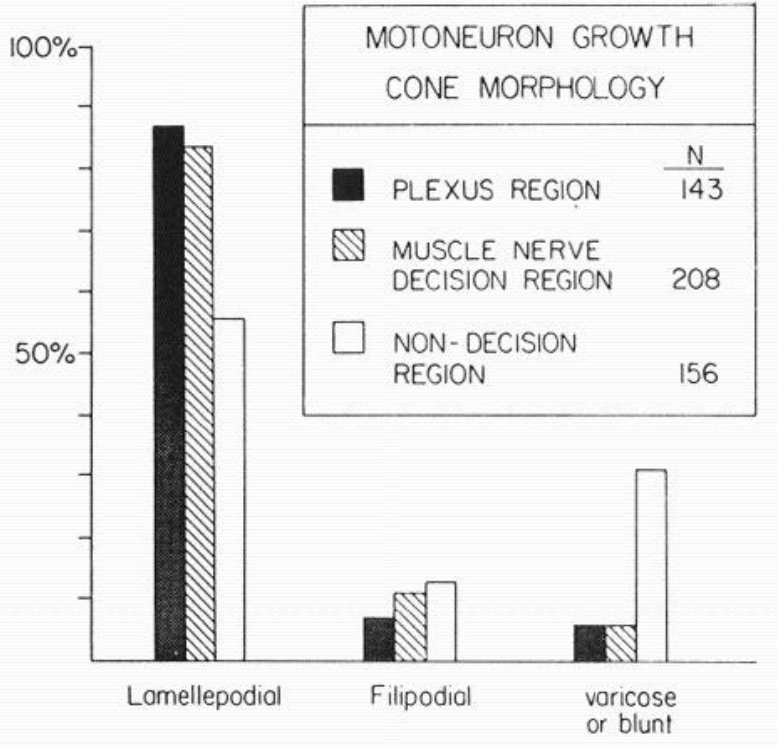

Figure 6. Motoneuron growth cones tend to be more lamellepodial in decision regions. The proportion of the populations identified in the key in different morphological types is shown.

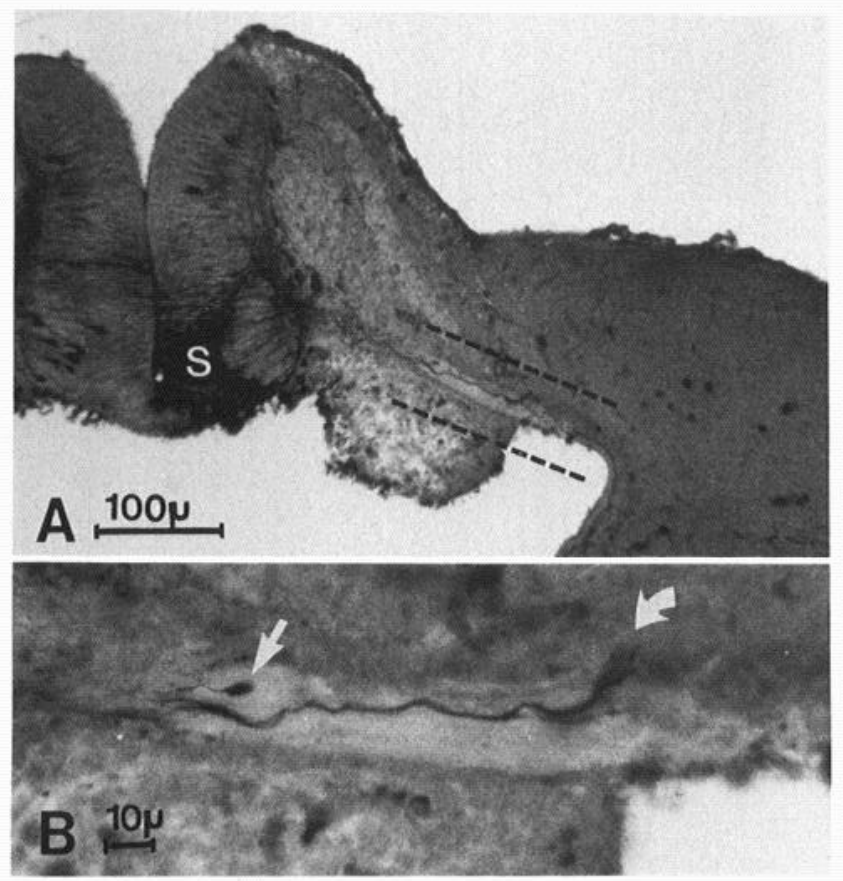

Figure 7. Typical motoneuron growth cone morphology in the spinal nerve and plexus. $A, H R P$ injected into the spinal cord $(s)$ has labeled two profiles in this section of a st 23.5 embryo. $B$. The spinal nerves and plexus areas between the dotted lines in $A$ are shown at higher magnification and illustrate the tendency for motoneuron growth cones to be small and varicose in the spinal nerves (straight arrow) and to become large and lamellepodial in the plexus region (curved arrow).

the trajectories of growth cones in the plexus region were of similar complexity at all stages of development.

For analysis of the trajectories of individual growth cones we selected 459 traced growth cones in which we had been able to record at least $50 \mu \mathrm{m}$ of profile proximal to the growth cone. We marked the profile at a point $50 \mu \mathrm{m}$ from the base of the growth cone. We counted the number of turns (defined as an alteration in trajectory by more than $25^{\circ}$ ) over this distance per profile and classified each turn in classes of 25 to 54,55 to 84,85 to 114 , and greater than $115^{\circ}$. We chose these classes because the turns tended to cluster around multiples of $30^{\circ}$, as has been observed by Bray (1973) in 

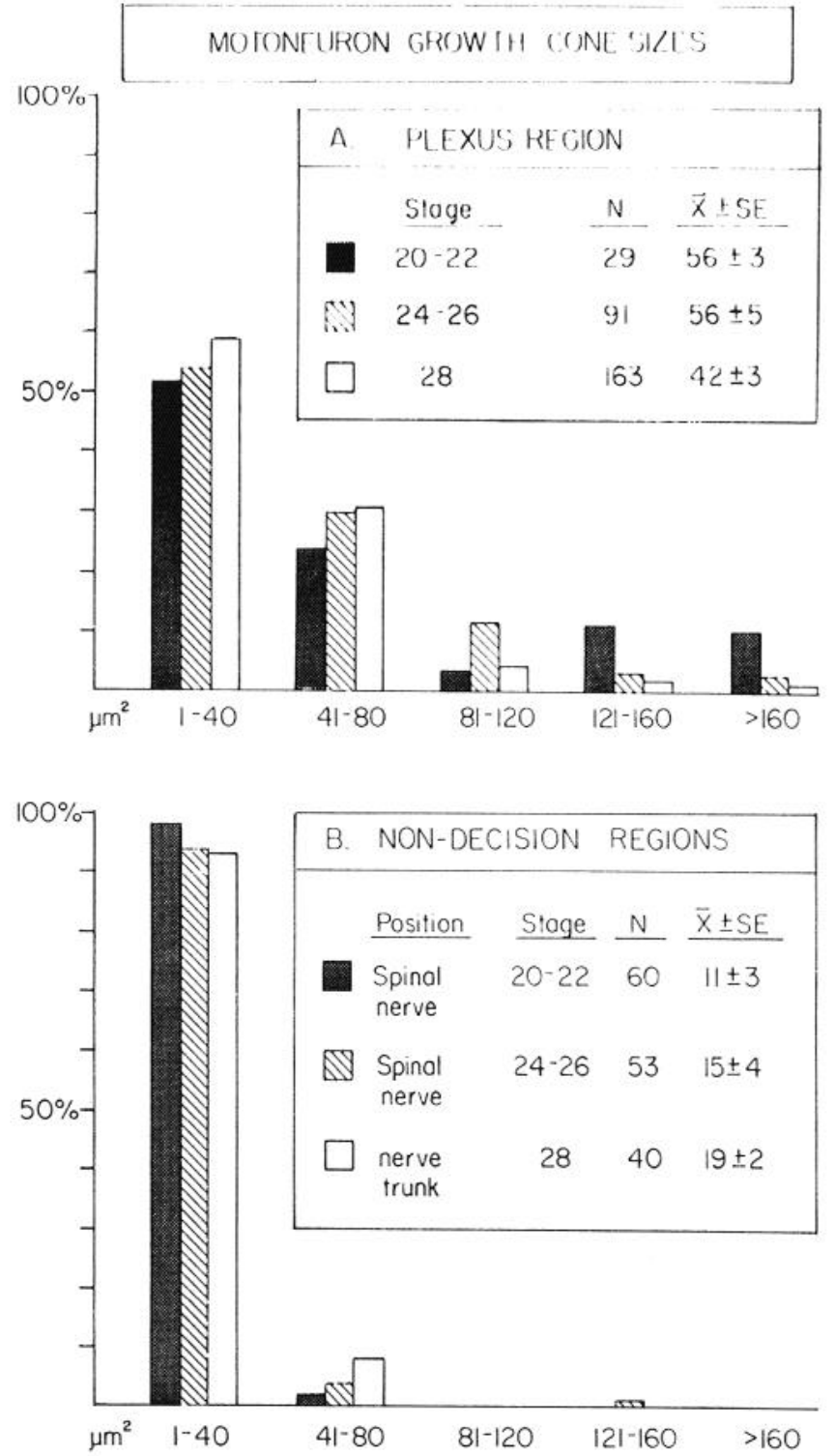

Figure 8. The size of motoneuron growth cones does not correlate with their stage of development. The proportion of each population at stages identified in the keys is shown in each size class in decision $(A)$ and non decision $(B)$ regions.

culture, and we were thus required to make fewer fine distinctions in these measurements

For analysis of growth cone size, we measured the maximum width and length of growth cones along axes perpendicular and parallel to the neurite. We expressed the size as the product of these figures, representing the "sampling area" of the growth cone, and we calculated the average sizes of populations. We report standard errors (SE) for each figure, since a large standard deviation is typical of motoneurons in decision regions and reflects the tendency for some growth cones to enlarge in this environment. We found, using a standard test of skewedness (Snedecor and Cochran, 1967), that the skewing toward larger sizes in decision regions was significant. We present much of the data as histograms, grouping populations into different size classes in order to reduce random error. Drawings made by each of us gave similar measurements, suggesting that we had little systematic error.

We maximized our chances of detecting growth cones by (1) examining sections cut perpendicular to the spinal cord and therefore parallel to the general direction of growth cone advancement, (2) examining regions where only a few profiles were labeled so that the very fine veils and filopodia were not obscured by other labeled profiles, and (3) determining that the labeled profile did not continue into an adjacent section. These precautions gave us a reasonable assurance that we were examining the growing tip of the nerve fiber.
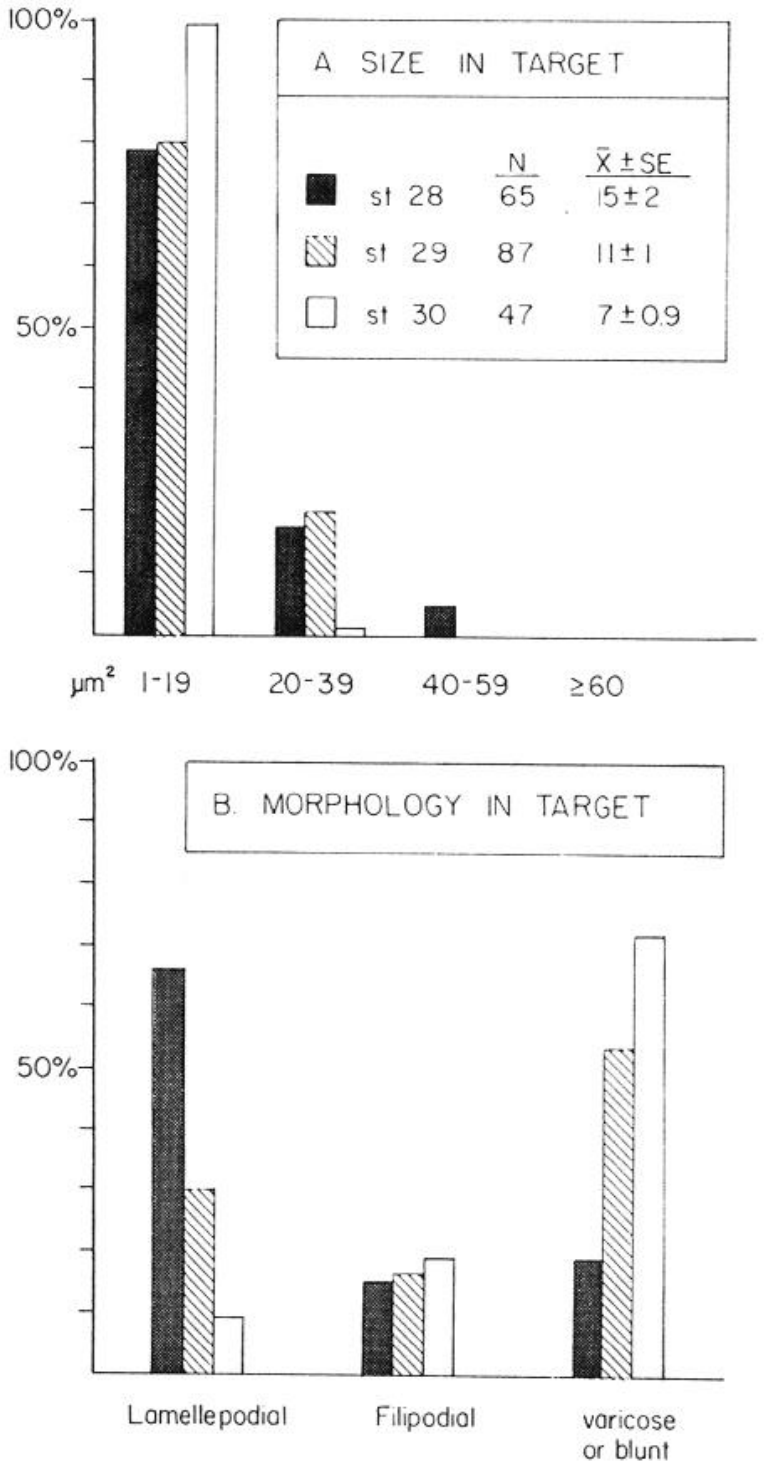

Figure 9. The size and morphology of motoneuron growth cones alter in the target. The proportion of growth cones of different size classes $(A)$ and morphologies $(B)$ is shown within the target at sequential stages that are identified in the key.

We classified the growth cones by morphology. Lamellepodial growth cones were wedge-shaped or possessed distinct veils (see Figs. $4 A$ and $11 D$ ). Filopodial growth cones were defined as those having prominent filopodia and lacking veils (see Fig. $4 C$ ). Varicose growth cones ended in a dark bead with occasional filopodia (see Figs. $4 B$ and $11 A$ ). Blunt growth cones generally had no specialized region at the tip of the neurite and were identified solely by their terminal position (see Fig. 11C).

The blunt class of growth cones may have included some incompletely labeled profiles which presented a similar morphology. We cannot rigorously exclude this possibility. However, the following observations suggest that many blunt ending profiles were growth cones and not simply incompletely filled profiles. (1) In no case did label decrease in intensity toward the end of the profile as it might with incomplete transport of HRP. (2) In similarly prepared specimens which were viewed at the electron microscopic level the HRP label appeared to fill the entire growth cone, including thin veils and filopodia (Tosney and Landmesser, 1985b). (3) Blunt growth cones were present in the nerve front at all stages; these were unlikely to be incompletely labeled profiles since electron microscopy shows that very few growth cones extend beyond the nerve front at any stage (Tosney and Landmesser. 1985b). (4) Blunt growth cones ceased to be present in the spinal nerves when all other types of growth cones were seen only more distally; and (5) we found that the proportion of blunt motoneuron growth cones varied with position in the embryo, whereas the proportion of blunt sensory growth 


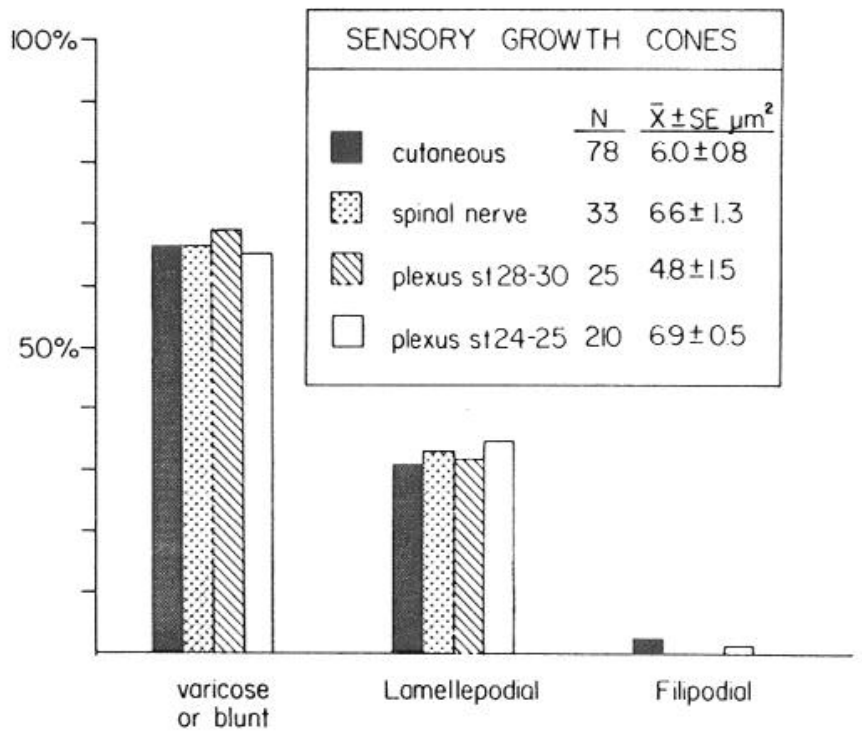

Figure 10. Morphology and size of sensory growth cones. The proportion of growth cones of different morphological types is shown in different regions that are identified in the key. There is no tendency for sensory growth cones to alter their size at different positions or different stages of development.

cones did not, an observation difficult to explain if these profiles reflect failure to fill the entire extent of the process.

\section{Results}

Complex trajectories in local decision regions. We find that motoneuron growth cones alter their trajectory dramatically within definable regions of the embryo that correspond to two areas where they are confronted with alternative pathways, the plexus region and the points where muscle nerves exit from the nerve trunks. The alteration in trajectory in these decision regions is particularly striking when viewed at the population level. When numerous profiles are labeled, a population can be seen to make, for instance, a $90^{\circ}$ turn into a particular muscle nerve (Fig. $1 A$ ). When a moderate number of neurites are labeled, the sharply defined turn is seen to be composed of individual turns at a variety of positions and angles (Fig. 1B). The sharp delineation of the turn at the population level is evidently due to a summation of divergent individual turns taking place in a very localized region. The idiosyncratic nature of the turns and their restricted localization are particularly obvious under similar labeling conditions in the plexus region. Figure 2, $A$ and $B$, for example, shows that relatively straight trajectories within the spinal nerves give way to a veritable snarl of profiles within the plexus region, whereas straight trajectories are resumed distally until a muscle nerve decision region is reached. Particularly in the plexus region, the complexity of turns appears to be greater than that necessary for straightforward entry into the dorsal or ventral nerve trunk pathway.

When individual growth cones are examined in decision regions, it is clear that they often cross over populations that are destined for other targets. In Figure $1 \mathrm{C}$, for example, a labeled growth cone

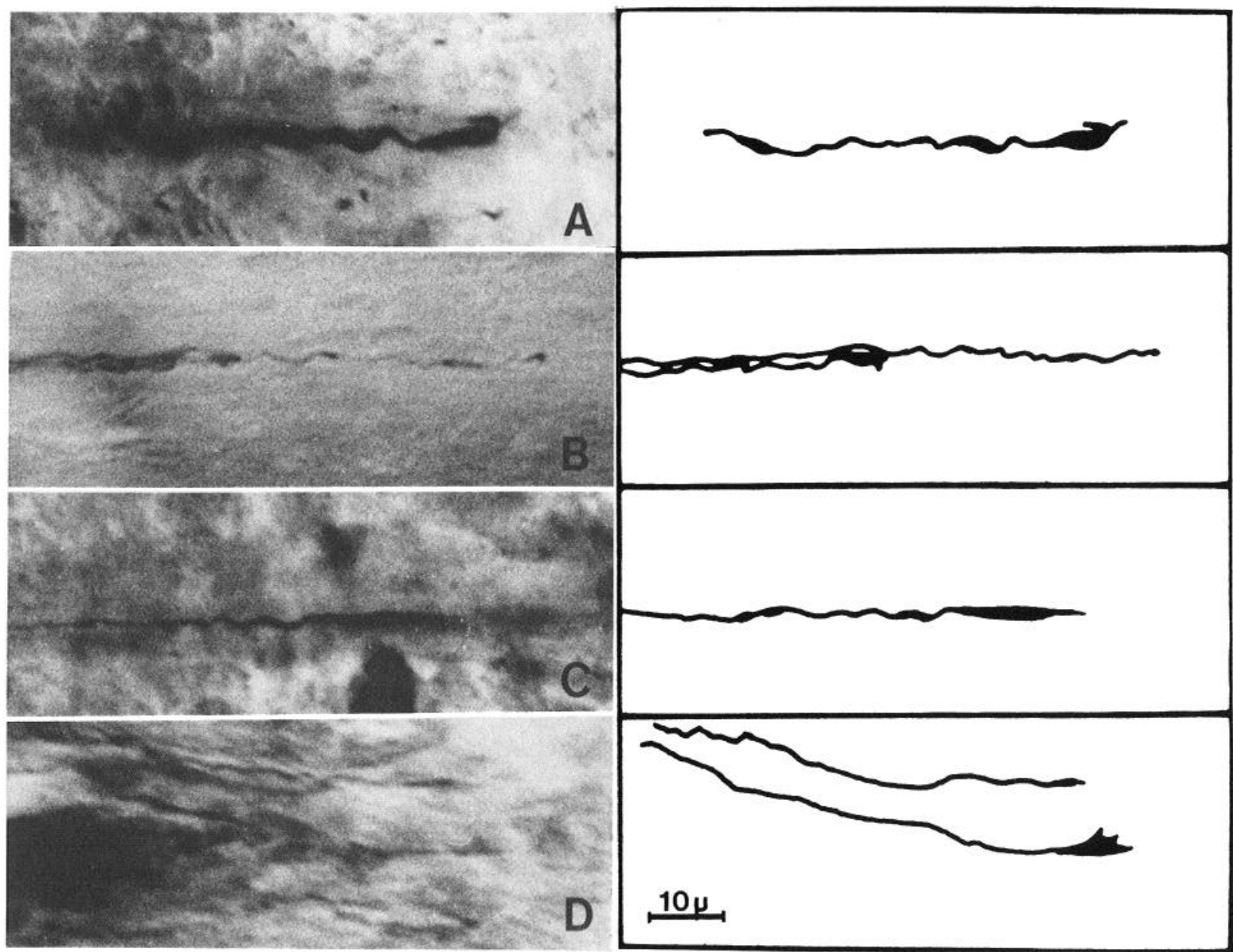

Figure 11. Sensory growth cones. Photographs and camera lucida drawings at $\times 100$ illustrating the typical morphologies of sensory growth cones show a large varicose growth cone from the spinal nerve $(A)$, a small varicose (right) and lamellepodial growth cone from a cutaneous nerve $(B)$, a blunt-ending growth cone from a cutaneous nerve $(C)$ and varicose $(t o p)$ and lamellepodial growth cone in the plexus region $(D)$. 


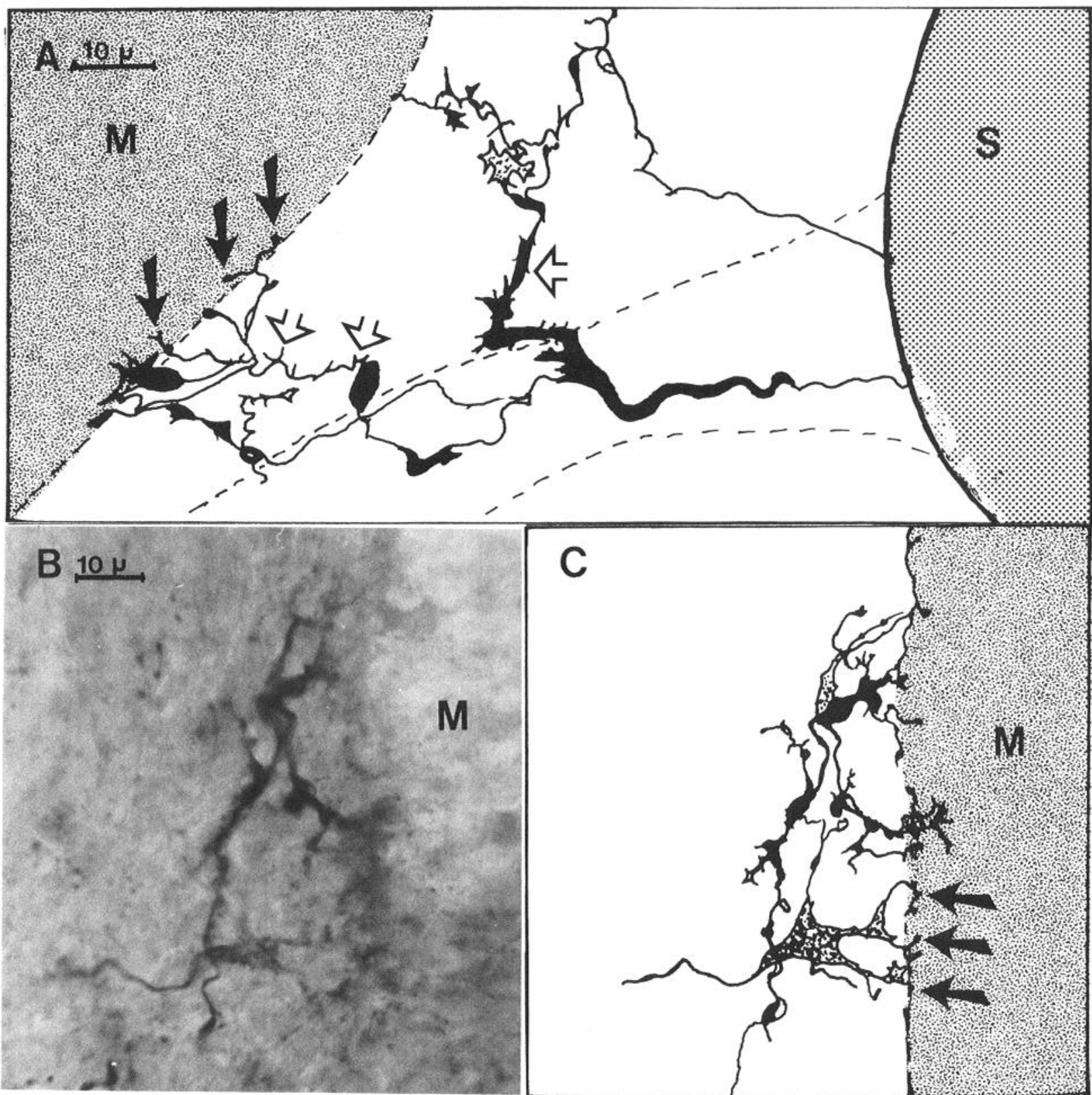

Figure 12. Myotomal growth cones. A, Myotomal growth cones do not exit from the spinal nerve at predictable regions as do the motoneuron growth cones that enter muscle nerves. The top profile in this camera lucida drawing has extended from the spinal cord $(S)$ immediately toward the myotome $(M)$, whereas others travel within the spinal nerve pathway (dashed lines) and emerge further distally. Some of the myotomal neurites have prominent retraction fibers (hollow arrows) once they enter the sclerotomal mesenchyme. The terminals tend to become small and varicose (solid arrows) once they enter their target. Photograph $(B)$ and camera lucida drawing $(C)$ show extensive ramification of myotomal growth cones. The complex growth cone at the bottom is mainly lamellepodial within the sclerotome; however, it extends processes into the myotome which become small and varicose (arrows in $C$ ). This alteration is typical of both myotomal and motoneuron growth cones as they enter the target.

within a muscle nerve decision region has turned and crossed over other neurites that are destined to leave the nerve trunk more distally. This growth cone cannot be passively channelled into the muscle nerve simply because it is caught in a "right hand turn lane;" it has actively moved across other neurites. It is also clear that the trajectory of this growth cone is not dictated by a gross physical feature of the environment-it has not, for instance, turned in order to avoid a mesenchyme cell. This case is typical; we find that growth cones within the decision regions often cross other axons and that there are no impediments within the decision regions that correlate with alterations in trajectory. A similar crossing of growth cones within the plexus region is illustrated in Figure $2, C$ and $D$. These observations suggested to us that individual growth cones within the decision regions were responding to specific cues in ways that were subject to detailed description.

Growth cone populations differ in decision and non-decision regions. To quantify the trajectory alterations at the level of individual growth cones, we examined camera lucida tracings of $\mathbf{4 5 9}$ growth cones. By analyzing only the terminal $50 \mu \mathrm{m}$ of the neurite, we thought it reasonably likely that the profile would closely reflect the recent trajectory of the growth cone. We measured the angle of turns and counted the number of turns per profile, having defined a turn as an alteration in trajectory of more than $25^{\circ}$.

We found a significant contrast in individual neurite trajectories within decision and non-decision regions (Fig. $3 A$ ). In all non-decision regions, the neurites projected with a generally straight course; only 

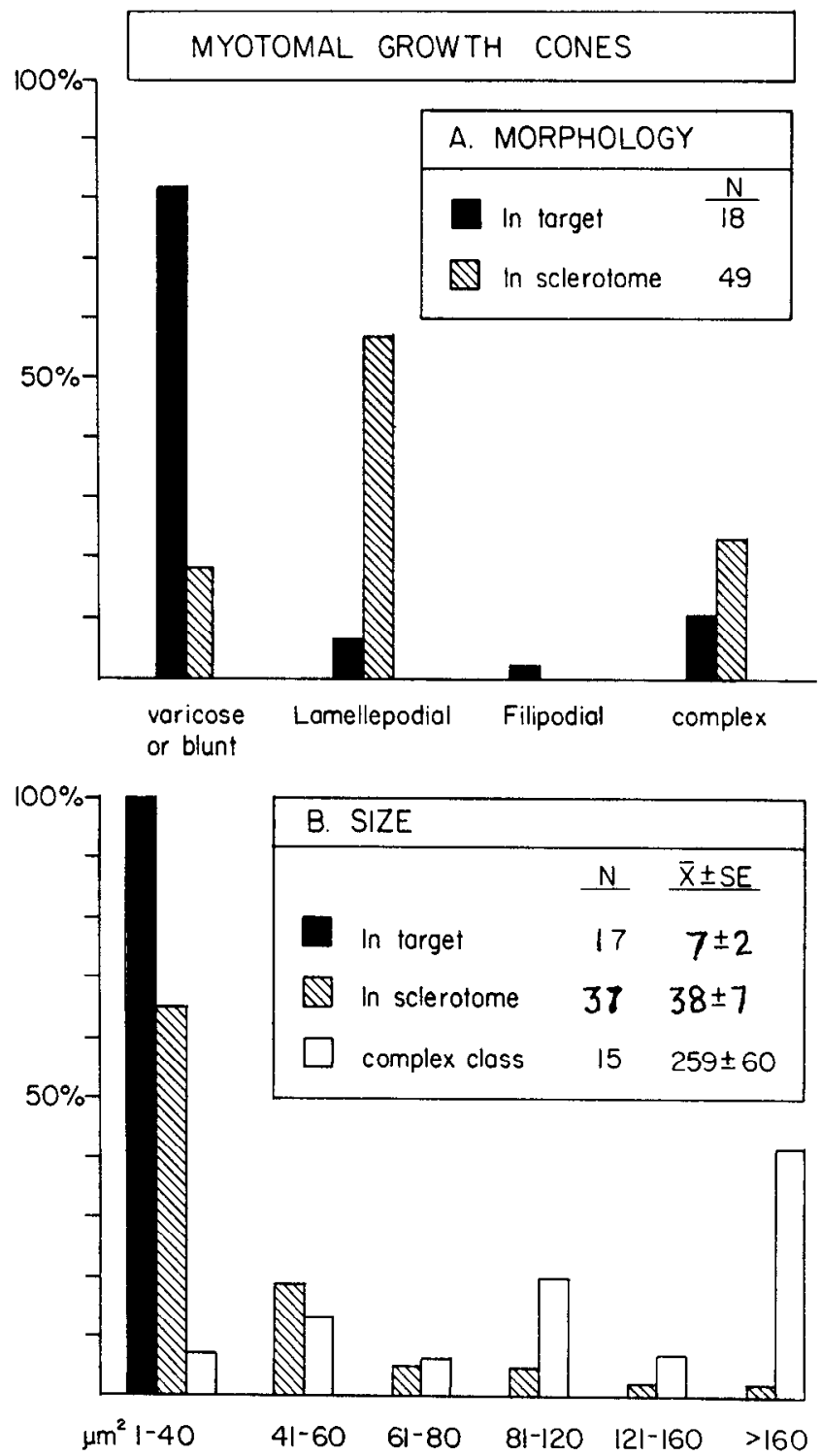

Figure 13. Morphology and size of myotomal growth cones. The proportion of each population identified in the key is given for each morphological classification $(A)$ and for each size class $(B)$.

$2 \%$ had more than one turn and $82 \%$ did not turn; only $3 \%$ of the turns were greater than $55^{\circ}$. In contrast, in the plexus region the neurite shape is often extremely complex: $55 \%$ turned at least once, and $15 \%$ turned more than once. In muscle nerve decision regions $55 \%$ turned at least once and $8 \%$ turned more than once.

When we analyzed in greater detail those profiles that had turned at least once, we found that the angle of the turns was generally larger within decision regions (Fig. $3 \mathrm{C}$ ). In the plexus region, $64 \%$ of the turns were greater than $55^{\circ}$ and $39 \%$ were greater than $85^{\circ}$; in muscle nerve decision regions, $38 \%$ were greater than $55^{\circ}$ and $7 \%$ were greater than $85^{\circ}$.

The complexity of the axonal trajectory within the plexus region did not differ significantly at different stages (Fig. 3B). The number of turns per profile was similarly distributed for the first growth cones to enter the plexus, the last to enter the plexus, and those during intermediate periods. This strongly suggests that the complex trajectories that we see are not due to profiles being passively pulled into tortuous shapes by the movement of local mesenchyme cells or other growth cones or by an increase in complexity in the environment with development; if this were the case, we would expect the trajectories to increase in complexity with time.

In 40 cases we observed what appeared to be a single profile that diverged to form two profiles. We believe that these were tightly fasciculated neighbors that had parted, rather than single axons that had branched, since we have not seen branching in electron micrographs at this stage (not shown) and since branching has not been detected electrophysiologically (Landmesser, 1978). To determine whether fiber order was maintained or tended to decay, we analyzed the degree of divergence of these fibers.

We found that the decay of fiber order was more pronounced in the plexus region; closely fasciculated fibers tended to move away from one another: $68 \%$ diverged more than $10 \mu \mathrm{m}$ over a $50-\mu \mathrm{m}$ trajectory and $32 \%$ ran parallel to one another (Fig. $3 D$ ). Since there was such a large decrease in fiber order, even within this small sample, we think it unlikely that neurites navigate through the plexus region by tightly fasciculating with a pioneering population that has preceded them.

In non-decision regions, only $9 \%$ of the closely fasciculated fibers diverged by more than $10 \mu \mathrm{m}$ and the majority ( $83 \%$ ) ran parallel, while the remaining converged. Those neurites that diverged from one another in the spinal nerves and nerve trunks generally remained within the same quadrant of the developing nerve. Since some divergences as well as turns were seen within non-decision regions, it appears that minor alterations of fiber order during the course of outgrowth can occur and that fiber order is not rigidly maintained.

Motoneuron growth cones in decision and non-decision regions. With a camera lucida, we traced 1338 growth cones from three populations: sensory growth cones, motoneuron growth cones that innervate the myotome (we will call these mytomal growth cones), and motoneuron growth cones that innervate the leg (which we will, for simplicity, call motoneuron growth cones). We measured their longest and widest dimensions and used the product of these figures as an indication of growth cone size or "sampling area." We also classified the growth cone morphology as lamellepodial, filopodial, or varicose/blunt. Examples of the different morphologies are shown in Figures 4 and 11.

We found that within the decision regions the distribution of size classes of motoneuron growth cones was significantly skewed at the $1 \%$ level toward larger sizes (Fig. 5). The average size of growth cones in decision regions was $45 \pm 1.5 \mu \mathrm{m}^{2}(N=407)$, more than double that of the average size in non-decision regions, $16 \pm 1.4$ $\mu \mathrm{m}^{2}(N=317)$. The average size of growth cones in different nondecision regions was not significantly different, and ranged from 13 \pm 3 to $19 \pm 2 \mu \mathrm{m}^{2}$. Less than $3 \%$ of the growth cones in any nondecision region were larger than $80 \mu \mathrm{m}^{2}$.

The largest motoneuron growth cones we have seen have been within the plexus region (Fig. $4 A$ ) where the average size was $48 \pm$ $2 \mu \mathrm{m}^{2}$ with $42 \%$ of the population greater than $40 \mu \mathrm{m}^{2}$ and $21 \%$ greater than $80 \mu \mathrm{m}^{2}$ (Fig. $5 \mathrm{~A}$ ). In muscle nerve decision regions, the average size of growth cones was $39 \pm 2 \mu \mathrm{m}^{2}$, with $34 \%$ larger than $40 \mu \mathrm{m}^{2}$ and $20 \%$ larger than $80 \mu \mathrm{m}^{2}$

The larger average size of motoneuron growth cones in decision regions is accompanied by a significant increase in the proportion of the population that is lamellepodial (see Fig. 6). In non-decision regions, a greater proportion ended blindly or in varicosities. Figure 7 nicely illustrates the tendency for motoneuron growth cones to be large and lamellepodial in the plexus region and small and varicose in the spinal nerves. Photographs and camera lucida tracings of motoneuron growth cones in different regions are shown in Figure 4.

There was no significant correlation between the average size of growth cones and their stage of development. The first growth cones to enter the plexus region did not differ significantly in average size from the last, and at all stages the average size of growth cones in decision regions was significantly larger than those measured in the same embryos in non-decision regions (Fig. 8). This strongly suggests that the first ("pioneering") population of growth cones does not differ in these attributes from those that grow out later.

The interaction between motoneuron growth cones and their targets was distinguished by a striking alteration in growth cone 


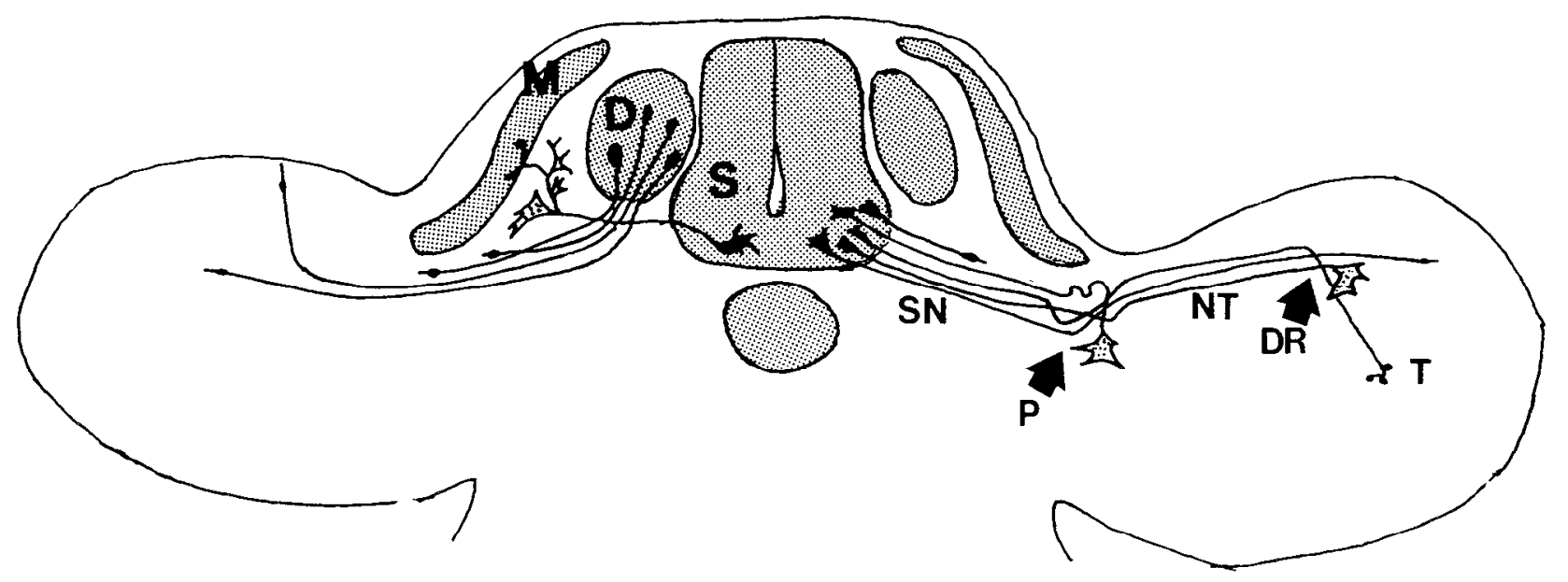

Figurc 14. Schematic summary of growth conc morphology and trajcctory. Myotomal growth concs (extending from the spinal cord (S) at left) are complex, unlikely to fasciculate, often have prominent retraction fibers along the neurite, and become small and beaded upon entering their target, the myotome $(M)$. Sensory growth cones (extending from the dorsal root ganglion $(D)$ at left) tend to be small and varicose at all positions and stages of outgrowth. The size and morphology of moloneuron growlh cones (right) are deperident on their posilion; they lend to be sinall and varicose in the spinal nerve $(S N)$ and nerve trunk $(N T)$, large and lamellepodial in the plexus region $(P)$ and muscle nerve decision region (DR), and to become very small and varicose within the target $(T)$. Motoneuron profiles abruptly alter their trajectories in decision regions.

morphology and a significant reduction in size with time (Fig. 9). The average size of growth cones in the target at early stages was similar to the size within the muscle nerve, $15 \pm 2 \mu \mathrm{m}^{2}$, and they were primarily lamellepodial. By st 30 , however, their size had decreased to $7 \pm 0.9 \mu \mathrm{m}^{2}$ and they had become small and beaded (Fig. 4D).

Sensory growth cones. Sensory growth cones tended to be small, averaging only $6.5 \pm 0.4 \mu \mathrm{m}^{2}(N=346)$, and $66 \%$ ended as simple naked fibers or in varicosities with a few filopodia (Figs. 10 and 11). Less than $0.01 \%$ were larger than $40 \mu \mathrm{m}^{2}$.

To determine whether the larger size of motoneuron growth cones in the decision regions is a response to some nonspecific feature of the environment, we asked whether sensory growth cones manifested a similar tendency to enlarge and become more lamellepodial as they entered the plexus region.

We orthogradely labeled dorsal root ganglion and motoneuron neurites on opposite sides in the same embryo and compared the growth cones within the plexus regions. We found that sensory growth cones, unlike those of motoneurons, did not alter their morphology when entering the plexus region but remained for the most part small and varicose. They did not differ significantly in size or morphology at different stages (st 24 to 25 versus st 28 to 30 ) or positions (the spinal nerves, plexus, or cutaneous nerves), as shown in Figure 10. These observations suggest that the enlargement of motoneuron growth cones in the decision regions is not due to some nonspecific aspect of the environment that affects all types of growth cones equally.

Myotomal growth cones. The growth cones of motoneurons that innervate the myotome are strikingly different from both the growth cones of leg-innervating motoneurons and those of sensory neurons. These growth cones tend to be large and lamellepodial, averaging $38 \pm 7.0 \mu \mathrm{m}^{2}$. Wc have classified one type of myotomal growth cones as "complex" (Fig. 12C). This class, which was not seen in other populations, tended to have multiple branches, more than one veil, or a veil and numerous filopodia at the tip of each neurite (Figs. 12 and 13). These aggregate growth cones averaged $259 \pm 60 \mu \mathrm{m}^{2}$ and are treated separately in the histograms of Figure 13; the average sizes of myotomal growth cones do not include this class. In a few instances we saw varicosities in the myotome and veils in the sclerotome that appeared to arise from the same profile (Fig. $12, A$ and $B$ ), suggesting that the morphology of the growth cone is very dependent on its local environment.

Some myotomal neurites possessed prominent retraction fibers that appeared to end on mesenchyme cells within the sclerotome (Fig. 12, $A$ and $C$ ). The myotomal neurites may also branch extensively. With orthograde injections it was difficult to tell how many of these neurons had been labeled; thus, we could not determine a ratio between the number of growth cones and somata. In one case, however, what appeared to be a single myotomal axon left the cord segment in which it was labeled by a more anterior ventral root which contained no other labeled neurites. This profile branched extensively within the sclerotome; it also extended over three sections $(75 \mu \mathrm{m})$ in the anterior-posterior plane.

These growth cones also differ from limb motoneurons in that they did not exit from the ventral roots at predictable regions, as motoneurons do when entering muscle nerves. Some extended immediately toward the myotome, whereas others traveled within the spinal nerve and emerged more distally (Fig. 12A). In addition, these neurites tended to fasciculate less than limb motoneurons and were often seen in contact with mesenchymal cells. The majority of the neurites were spread within the sclerotome at early stages, and a distinct myotomal nerve was not apparent until st 26 . These growth cones also emerged from the spinal cord over a longer period than do leg-innervating motoneurons: we have seen them from st 20 through 30 , whereas leg-innervating motoneuron growth cones have all reached the plexus region by st 26 . The motoneuron pool position for these neurons lies medial to the leg-innervating motoneurons (Tosney and Landmesser, 1985b).

Myotomal growth cones, like other motoneurons, altered significantly once they entered their target, becoming smaller and varicose (Fig. 13). Since these alterations in myotomal growth cone morphology and size within the target initially occurred at younger stages than did the similar alteration in leg-innervating motoneurons, a global alteration in the embryonic environment does not appear to be the cause of alterations in growth cone shape. This observation reinforces our view that such changes reflect growth cone responses to specific molecular cues within the local environment.

\section{Discussion}

Our results, summarized in Figure 14, show that different neuronal populations have characteristic growth cone populations and that the morphology of the motoneuron growth cone population is significantly different in the regions we have chosen to call decision and non-decision regions. We suggest that the tendencies for motoneuron growth cones to enlarge, become more lamellepodial, and pursue convoluted trajectories within decision regions are either 
direct responses to specific local cues or responses to some more general aspect of the decision region that allows growth cones to respond to specific cues.

Motoneuron growth cones. The correlation between the position and morphology of motoneuron growth cones suggests that their morphology is modulated by the immediate environment. Similar correlations between the size and location of growth cones has been seen among the sensory population in Xenopus (Roberts and Taylor, 1983) as well as in invertebrate systems (Taghert et al., 1982; Bentley and Caudy, 1984). A particularly striking correlation in the present paper is the decrease in size and alteration to a more varicose morphology by both myotome- and leg-innervating motoneurons upon entering their targets. These alterations presumably reflect the transition from growth cone advancement to the formation of stable synapses.

The most interesting correlation we see is between the position and size of growth cones of motoneurons that innervate the leg. The increase in the average size of these growth cones within the decision regions is a consequence of more growth cones expressing the larger lamellepodial form. We think it likely that we are sampling a dynamic process in which all or a large proportion of the growth cones enlarge cyclically within the decision regions, and it is unlikely that these are a small subset of "pioneering" growth cones that alone are capable of enlargement. This assumption is supported by cinematography in other systems, which shows rapid alterations in the morphology of cultured growth cones: for instance, large lamellepodial growth cones may rapidly form varicosities that often remain immobile for several minutes before resuming motile activity (Tosney and Wessells, 1983). The very large lamellepodial forms of growth cones described by Argiro et al. (1984) have a lifetime of 5 to 15 min, during which time they advance with great rapidity (up to 250 $\mu \mathrm{m} / \mathrm{hr}$ ) before reverting to a slower moving filopodial morphology. Since, in addition, the enlarged growth cones are seen at all stages of outgrowth, they are unlikely to be an early set of pioneering fibers with unique pathfinding abilities.

The complex trajectories of motoneuron neurites in decision regions are a direct correlate of the necessity for these growth cones to alter their direction of travel in order to assume a correct fiber order and enter the proper nerve. However, the trajectories are more complex than would be predicted by a parsimonious model in which populations are passively channeled into the proper pathway (see, for instance, Horder and Martin, 1978). For example, growth cones may turn more than once, particularly within the plexus region. In addition, growth cones do not turn in concert (see also Tosney and Landmesser, 1985a), often cross other populations, and turn at diverse angles. These observations strongly suggest that population phenomena are not vital to the allocation of growth cones into correct pathways and that growth cones may turn actively and independently of one another in decision regions. This implies that alterations in growth cone trajectories are individual responses to specific cues.

How might a response to specific cues be mediated? Evidence that growth cones will move onto a more adhesive substratum supports a popular model in which a gradient of adhesiveness guides growth cones in a particular direction (see Letourneau, 1975b). However, since growth cones from different populations must move in different and specific directions within decision regions, a single adhesive gradient is insufficient to explain specific pathfinding in this system. A more plausible mechanism incorporates the specific recognition of molecular cues (cf. Sperry, 1963).

The concept of guidance by specific molecular cues does not implicate any one mechanism for altering the direction of growth cone advancement. Once a cue is recognized, a directional response could result from a variety of different mechanisms. For example, a growth cone's "recognition" of cell surface molecules may involve increased adhesion of filopodia onto cells bearing these molecules (cf. Fallon, 1985). Thus, neurons could be guided, as described by Letourneau $(1975 a, b)$, by a hierarchy of adhesivities present in the in vivo environment (see, for example, Berlot and Goodman, 1984). Another possibility is that diffusible molecular cues (Gunderson and Barrett, 1980) are arrayed as concentration gradients. Such molecules could act by increasing filopodial adhesion on the uphill side of the gradient. Alternatively, they could act independenty of adhesion; for instance, by causing an increased protrusion of cell surface membrane on one side of the growth cone. This would also tend to result in growth cone movement in a preferred direction (see Bray, 1973, 1979).

The fact that growth cones were shown to be larger and to make specific changes in their direction of growth in certain regions could indicate that specific cues are present only in these regions. Alternatively, cues may be present more globally but axons may be prevented from responding to them by other constraints. There is suggestive evidence that cues in the limb extend for some distance beyond the target and muscle nerve decision regions. For example, growth cones channeled into foreign limb regions can abruptly alter their trajectories and innervate their correct targets if this is not too distant (Lance-Jones and Landmesser, 1981a, b; see also Hollyday, 1981; Summerbell and Stirling, 1981; Lance-Jones, 1982).

There is also evidence for the existence of pathway constraints. Ferguson (1983) found that after proximal rotation of the limb bud about the dorsoventral axis, motoneurons made adjustments in their direction of outgrowth in the plexus region and subsequently innervated their appropriate targets. However, Whitelaw and Hollyday (1983), performing similar rotations more distally in the limb, found that motoneurons were unable to compensate. Presumably, once having sorted out into compact and separate nerves, the axons were unable to respond to specific cues at this level due to some as yet undefined constraints.

One pathway constraint that could limit trajectory alterations in response to cues is strong interneuronal associations. Trajectory alterations would be enhanced if the strength of growth cone-nerve fiber interactions was lowered within decision regions by a reduction in substances, such as NCAM, that mediate fiber-fiber association (see Rutishauser and Edelman, 1980), and/or by a competitive increase in the adhesiveness of the surrounding non-neuronal substratum (see Fraser, 1980). We are currently collaborating with U. Rutishauser and M. Watanabe to determine whether the type or distribution of NCAM varies along these pathways during outgrowth.

We have also used electron microscopic and histological techniques to describe the physical environment during neurite outgrowth (Tosney and Landmesser, 1985b). We found that decision and nondecision regions are not markedly different from one another on morphological criteria. Both regions contain a loose aggregation of unoriented mesenchyme cells which could differ in chemical properties, a question we were unable to address with anatomical techniques. However, we obtained data in support of some general environmental constraints that help to delineate the permissive pathways for growth cone advancement, two of these being strong interneuronal adhesiveness and a differential distribution of glycosaminoglycans.

The alterations in growth cone morphology that we report here do not allow us to distinguish among the possible mechanisms of axonal guidance. For instance, enlargement of growth cones is consistent both with the directional addition of surface in response to a chemical attractant and with an increase in adherence to the substratum that is mediated by recognition of a specific cue or by a general increase in adhesivity to the substratum within decision regions. The enlargement has an intriguing implication in that a larger size could allow the growth cone to contact a more extensive portion of its environment and might enhance the growth cone's access to positional information.

If the morphology of growth cones in decision regions is a direct correlate of the local presence of molecular cues, we might expect that only the appropriate growth cones would alter their morphologies and trajectories in muscle nerve decision regions. Technical limitations prevented us from determining whether this was so, both 
because the enlargement of growth cones is a population phenomenon and because we could not unequivocally identify the destiny of a particular growth cone until it had moved beyond the muscle norve decision region. This issue can be addressed by experimental manipulations that channel growth cones into foreign limb regions and result in their indiscriminate projection down muscle nerves (see, for instance, Lance-Jones and Landmesser, 1981b). Following such manipulations, all motoneuron growth cones within muscle nerve decision regions would be inappropriate. These growth cones should also enlarge if enlargement is due to some general feature of decision regions that affect all motoneuron growth cones equally; if growth cones do not enlarge in foreign decision regions, this would suggest that enlargement is associated with a response to specific cues.

Sensory neurons. In view of the experimental evidence showing that the sensory population requires motoneurons for proper outgrowth and may not be utilizing the same cues as motoneuron growth cones (Landmesser and Honig, 1982; Landmesser et al., 1983), we were not surprised to find that sensory growth cone morphology was similar in motoneuron decison and non-decision regions. This observation suggests that the enlargement of moto neuron growth cones in decision regions is not a response to some highly nonspecific aspect of the environment that affects all species of growth cones equally, and supports our interpretation that the morphological alterations among motoneuron growth cones in de cision regions may be an important correlate of their specific guidance.

Our observations also lend support to the suggestion that sensory neurons may utilize motoneurons as a substratum for proper outgrowth (Honig, 1980, 1982). The sensory growth cones' consistently small size and the presence of a few forward-directed filopodia suggest that they are following linear elements in their pathways; they therefore resemble growth cones fasciculating on neurites in vitro (Wessells et al., 1981; Tosney and Wessells, 1983) and in vivo (Roberts, 1976; Macagno, 1978; Bastiani et al., 1984; Raper et al., 1983b; Shankland and Bentley, 1983). In suggesting this, we do not mean to imply a highly specific association on a single fiber basis, like that shown to be important in the grasshopper CNS (Raper et al., 1983a, 1984; Bastiani et al., 1984). If this were so, we might expect sensory neurites to closely follow all of the twists and turns of motoneuron neurites through decision regions, which is contrary to our impression that the sensory neurite trajectories are less convoluted (see Fig. 14). Alternatively, while sensory growth cones may adhere to motoneuron fibers, the sensory neurites may not; if so, their trajectories would not mirror the motoneurons' trajectories. It is possible that sensory growth cones enlarge at the point where cutaneous nerves diverge from mixed nerve trunks, since at this point they would have to leave their association with motoneurons. However, the size of our samples of sensory growth cones in these regions was insufficient to resolve this possibility.

Myotomal growth cones. The growth cones from neurons that innervate the myotome appear distinctly different from other populations. At all points proximal to their targets they tend to be larger than other growth cones, are often extremely complex, fasciculate less often, and exit from the spinal nerves at divergent positions. The large size and divergent turns are features that are also common to leg-innervating motoneuron growth cones examined in decision regions, and could be taken as an argument against our thesis that these morphological features are related in some manner to the specific guidance of motoneuron growth cones.

Alternatively, the environment proximal to the plexus region may be a decision region for these growth cones; they may respond here to environmental features similar to those that encourage motoneuron, but not sensory, growth cone alterations in other decision regions. For instance, they may respond directly to molecular cues specific for myotomal growth cones. The proximity of the myotomal target, a possible source of specific cues, is in accord with this possibility. The observations on myotomal growth cones are also consistent with a less specific response to decision regions: these growth cones may have an intrinsically lower strength of fiberfiber interactions, a possibility consistent with their observed lower degree of fasciculation throughout the course of their travel, or a greater adhesivity to the sclerotomal cells, a possibility consistent with the large size of these growth cones.

\section{References}

Argiro, V., M. B. Bunge, and M. I. Johnson (1984) Correlation between growth cone form and movement and their dependence on neuronal age. J. Neurosci. 4: 3051-3062.

Bastiani, M. J., J. A. Raper, and C. S. Goodman (1984) Pathfinding by neuronal growth cones in grasshopper embryos. III. Selective affinity of the $G$ growth cone for the $P$ cells within the A/P fascicle. J. Neurosci. 4 : 2311-2328.

Bentley, D., and M. Caudy (1983) Pioneer axons lose directed growth after selective killing of guidepost cells. Nature 304: 62-65.

Bentley, D., and M. Caudy (1984) Navigational substrates for peripheral pioneer growth cones: Limb-axis polarity cues, limb-segment boundaries, and guidepost neurons. Cold Spring Harbor Symp. Quant. Biol. 48: 573585.

Bentley, D., and H. Keshishian (1982) Pathfinding by peripheral pioneer neurons in grasshoppers. Science 218: 1082-1088.

Berlot, J., and C. S. Goodman (1984) Guidance of peripheral pioneer neurons in the grasshopper: Adhesive hierarchy of epithelial and neural surfaces. Science 223: 493-496.

Bonhoeffer, F., and J. Huf (1982) In vitro experiments on axon guidance demonstrate an anterior posterior gradient on the tectum. EMBO J. 1: 417-431.

Bray, D. (1973) Branching patterns of individual sympathetic neurons in culture. J. Cell Biol. 56: 702-712.

Bray, D. (1979) Mechanical tension produced by nerve cells in tissue culture. J. Cell Sci. 37: 391-410.

Bray, D. (1983) Axonal growth in response to experimentally applied me chanical tension. Dev. Biol. 102: 379-389.

Fallon, J. S. (1985) Preferential outgrowth of central nervous system neurites on astrocytes and Schwann cells as compared to non-glial cells in vitro. J. Cell Biol. 100: 198-207.

Ferguson, B. A. (1983) Development of motor innervation of the chick following dorsal-ventral limb bud rotations. J. Neurosci. 3: 1760-1772.

Fraser, S. E. (1980) A differential adhesion approach to the patterning of nerve connections. Dev. Biol. 79: 453-464.

Goodman, C. S., J. A. Raper, R. Ho, and S. Chang (1982) Pathfinding by neuronal growth cones in grasshopper embryos. In Cytochemical Methods in Neuroanatomy: Proceedings, V. Chan-Palay, ed., pp. 461494, Alan R. Liss, Inc., New York.

Gunderson, R. W., and J. N. Barrett (1980) Characterization of the turning response with dorsal root neurites toward nerve growth factor. J. Cell Biol. 87: 546-554.

Hamburger, V., and H. L. Hamilton (1951) A series of normal stages in the development of the chick embryo. J. Morphol. 88: 49-82

Ho, R. K., E. E. Ball, and C. S. Goodman (1983) Muscle pioneers: Large mesodermal cells that erect a scaffold for developing muscles and motoneurons in grasshopper embryos. Nature 301: 66-68.

Hollyday, M. (1981) Rules of motor innervation in chick embryos with supernumerary limbs. J. Comp. Neurol. 202: 439-465.

Hollyday, M. (1983) Development of motor innervation of chick limbs. In Limb Development and Regeneration, J. Fallon and A. Caplan, eds., Part A, pp. 183-193, Alan R. Liss, Inc., New York.

Honig, M. G. (1980) Development of sensory projection patterns in chick hind limb. Ph.D. dissertation, Yale University, New Haven.

Honig. M. G. (1982) The development of sensory projection patterns in embryonic chick hindlimb. J. Physiol. (Lond.) 330: 175-202.

Horder, T. J., and K. A. C. Martin (1978) Morphogenetics as an alternative to chemospecificity in the formation of nerve connections. In Society for Experimental Biology Symposium, Cell-Cell Recognition, A. S. G. Curtis, ed., Vol. 32, pp. 275-358, Cambridge University Press, Cambridge, England

Lance-Jones, C. (1982) Motoneuron connectivity in embryonic chick limbs with an altered complement of muscle. Soc. Neurosci. Abstr. 8: 435

Lance-Jones, C., and L. Landmesser (1981a) Pathway selection by chick lumbosacral motoneurones during normal development. Proc. R. Soc. Lond. (Biol.) 214: 1-18.

Lance-Jones, C., and L. Landmesser (1981b) Pathway selection by embryonic chick motoncurones in an cxpcrimentally altered environment. Proc. R. Soc. Lond. (Biol.) 214: 19-52. 
Landmesser, L. (1980) The generation of neuromuscular specificity. Annu. Rev. Neurosci. 3: 279-302.

Landmesser, L. (1984) The development of specific motor pathways in the chick embryo. Trends Neurosci. 7: 336-339.

Landmessser, L., and M. Honig (1982) The effect of motoneuron removal on sensory neuron outgrowth in chick hindlimb. Soc. Neurosci. Abstr. 8: 929.

Landmesser, L. T. (1978) The development of motor projection patterns in the chick hindlimb. J. Physiol. (Lond.) 284: 391-414.

Landmesser, L. T., M. J. O'Donovan, and M. Honig (1983) The response of hindlimb motor and sensory neurons to an altered periphery. In Limb Development and Regeneration, J. Fallon and A. Caplan, eds., Part A, pp. 207-216, Alan R. Liss, Inc., New York.

Letourneau, P. C. (1975a) Cell-to-substratum adhesion and guidance of axonal elongation. Dev. Biol. 44: 92-101.

Letourneau, P. C. (1975b) Possible roles for cell-to-substratum adhesion in neuronal morphogenesis. Dev. Biol. 44: 77-91.

Lewis, J., A. Chevallier, M. Kieny, and L. Wolpert (1981) Muscle nerves do not develop in chick wing devoid of muscle J. Embryol. Exp. Morphol. 64: 211-232.

Lewis, J., L. Al-Ghaith, and G. Swanson (1983) The control of axon outgrowth in the developing chick wing. In Limb Development and Regeneration, J. Fallon and A. Caplan, eds., Part A, pp. 195-205, Alan R. Liss, Inc., New York.

Luduena, M. A. (1973) The growth of spinal ganglion neurons in serum-free medium. Dev. Biol. 33: 470-476.

Macagno, E. R. (1978) Mechanism for the formation of synaptic projections in the arthropod visual system. Nature 275: $318-320$.

Morris, D. G. (1978) Development of functional motor innervation in supernumerary hindlimbs of the chick embryo. J. Neurophysiol. 41: 1450-1464.

Ramón y Cajal, S. (1937) Recollections of my life. ( $\mathrm{H}$. Craigie, transl.) in Memoirs of the American Philosophical Society, Vol. 8, pp. 368-369, American Philosophical Society, Philadelphia.

Raper, J. A., M. Bastiani, and C. S. Goodman (1983a) Pathfinding by neuronal growth cones in grasshopper embryos. I. Divergent choices made by the growth cones of sibling neurons. J. Neurosci. 3: 20-30.

Raper, J. A., M. Bastiani, and C. S. Goodman (1983b) Pathfinding by neuronal growth cones in grasshopper embryos. II. Selective fasciculation onto specitic axonal pathways. J. Neurosci. 3: 31-41.

Raper, J. A., M. J. Bastiani, and C. S. Goodman (1984) Pathfinding by neuronal growth cones in grasshopper embryos. IV. The effects of ablating the $A$ and $P$ axons upon the behavior of the $G$ growth cone. J. Neurosci. 4: $2329-2345$

Roberts, A. (1976) Neuronal growth cones in an amphibian embryo. Brain Res. 118: 526-530.

Roberts, A., and J. S. H. Taylor (1983) A study of the growth cones of developing embryonic sensory neurites. J. Embryol. Exp. Morphol. 75: 31-47.

Rutishauser, U., and G. M. Edelman (1980) Effects of fasciculation on the outgrowth of neurites from spinal ganglia in culture. J. Cell Biol. 87: 370378 .

Shankland, M., and D. Bentley (1983) Sensory receptor differentiation and axonal pathfinding in the cercus of the grasshopper embryo. Dev. Biol. 97: $468-482$.

Snedecor, G. W., and W. G. Cochran (1967) Statistical Methods, Ed. 6, The lowa State University Press, Ames, IA.

Sperry, R. W. (1963) Chemoaffinity in the orderly growth of nerve tiber patterns and projections. Proc. Natl. Acad. Sci. U. S. A. 50: 703-710.

Summerbell, D., and R. V. Stirling (1981) The innervation of dorsoventrally reversed chick wings: Evidence that motor axons do not actively seek out their appropriate targets. J. Embryol. Exp. Morphol. 61: 233-247.

Taghert, P. H., M. J. Bastiani, R. K. Ho, and C. S. Goodman (1982) Guidance of pioneer growth cones: Filopodial contacts and coupling revealed with an antibody to lucifer yellow. Dev. Biol. 94: 391-399.

Tosney, K. W., and L. T. L andmesser (1984) Pattern and specificity of axonal outgrowth following varying degrees of chick limb bud ablation. J. Neurosci. 4: 2518-2527.

Tosney, K. W., and L. T. Landmesser (1985a) Specificity of motoncuron growth cone outgrowth in the chick limb. J. Neurosci. 5: 2336-2344.

Tosney, K. W., and L. T. Landmesser (1985b) Normal development of the gross anatomical nerve pattern in the chick hindlimb. Dev. Biol. 109: 193214.

Tosney, K. W., and N. K. Wessells (1983) Neuronal motility: The ultrastructure of veils and microspikes correlates with their motile activities. J. Cell. Sci. 61: 389-411.

Wessells, N. K., P. C. Letourneau, R. P. Nuttall, M. Luduena-Anderson, and J. M. Geiduschek (1981) Responses to cell contacts between growth cones, neurites and ganglionic non-neuronal cells. J. Neurocytol. 9: 647664 .

Whitelaw, V. and M. Hollyday (1983). Neural pathway constraints in the motor innervation of the chick limb following dorsoventral rotations of distal limb segments. J. Neurosci. 3: 1226-1233. 